\title{
In vitro suppression of oral squamous cell carcinoma growth by ultrasound-mediated delivery of curcumin microemulsions
}

This article was published in the following Dove Press journal:

International Journal of Nanomedicine

20 February 2012

Number of times this article has been viewed

\author{
Hung-Yin Lin ${ }^{1,2}$ \\ James L Thomas ${ }^{3}$ \\ Huan-Wen Chen' \\ Chih-Min Shen ${ }^{4}$ \\ Wen-Jen Yang ${ }^{2}$ \\ Mei-Hwa Lee ${ }^{4}$ \\ 'Department of Chemical and \\ Materials Engineering, National \\ University of Kaohsiung, Kaohsiung, \\ Taiwan; ${ }^{2}$ Institute of Biotechnology, \\ National University of Kaohsiung, \\ Kaohsiung, Taiwan; ${ }^{3}$ Department of \\ Physics and Astronomy, University \\ of New Mexico, Albuquerque, NM; \\ ${ }^{4}$ Department of Materials Science \\ and Engineering, I-Shou University, \\ Kaohsiung, Taiwan
}

\begin{abstract}
There is increasing interest in using natural products as anticancer agents, as many have antioxidative properties that may help to prevent cellular damage that can lead to cancer. In addition, there is the expectation that many natural products will have low toxicity and few side effects. However, most anticancer and antioxidative agents are hydrophobic, reducing their bioavailability in vivo and making them problematic to deliver. Curcumin provides a good model system for study. In low doses it shows both anticancer and antioxidation effects, whereas in high doses and delivered locally it could be cytotoxic for cancer cells. In this paper, curcumin microemulsions were formed with food-grade chemicals, including soybean lecithin, soybean oil, and Tween 80, a Food and Drug Administration-approved surfactant. The optimized composition formed curcumin microemulsions with a mean size of $40-50 \mathrm{~nm}$, carrying a concentration of curcumin as high as $15 \mu \mathrm{M}$. The stability of curcumin microemulsions refrigerated at $5^{\circ} \mathrm{C}$ over at least 968 days was assessed by size distribution and zeta potential. The effects of lowfrequency ultrasound on two oral squamous cell carcinoma cell lines (OSCC-4 and OSCC-25), and the synergy between treatment with curcumin microemulsions and low-frequency sonic stimulation, were tested. Finally, microscopic imaging of the cells confirmed the toxic effects of the curcumin microemulsions, showing damaged and ruptured cells after treatment. Brief exposure to the curcumin-containing microemulsions did have cytotoxic effects, but the addition of ultrasound strongly enhanced those effects, especially on OSCC-25 cells.
\end{abstract}

Keywords: oral squamous cell carcinoma (OSCC), curcumin, microemulsion, ultrasound, controlled release

\section{Introduction}

Traditional natural products have recently been extensively examined because they show few side effects and have powerful antioxidation, anti-inflammation, and cancerpreventing properties. ${ }^{1}$ For example, half a century ago, curcumin and its family of related compounds were reported to have antibacterial effects, and many researchers have subsequently studied their antioxidation and anticancer properties. However, the curcumin compounds are polyphenols and may not be very stable or soluble in water. ${ }^{2}$ They have been delivered orally, using a transdermal patch, and by injection. ${ }^{3}$ Numerous formulations of curcumin have recently been developed, including, for example, solid lipid curcumin particles, ${ }^{4}$ curcumin submicrometer dispersions,${ }^{5}$ poly(ethylene glycol)-magnetic nanoparticles-curcumin, ${ }^{6}$ curcumin poly( $n$-butylcyanoacrylate) nanoparticles, ${ }^{7}$ self-microemulsifying liquid and pellets of curcumin, ${ }^{8}$ curcumin polyvinylpyrrolidone nanoparticles, ${ }^{9}$ and liposome-encapsulated curcumin. ${ }^{10}$ Carriers with high curcumin encapsulation, low cost, and high biocompatibility may be attractive
Correspondence: Mei-Hwa Lee Department of Materials Science and Engineering, I-Shou University, Nol, Sec I, Syuecheng Rd, Dashu District, Kaohsiung City 8400I,Taiwan Tel $+886(7) 657771$ l ext 3128 Fax +886(7) 6578444

Email meihwalee@ntu.edu.tw 
for dietary supplements, cancer prevention, and anticancer applications.

Plasma antioxidant activities of curcumin have been measured to determine the bioavailability in Sprague-Dawley rats, using self-microemulsifying liquid and pellet formulations of liposome-encapsulated curcumin, ${ }^{8}$ and male Wistar-strain rats. Curcumin poly(n-butylcyanoacrylate) nanoparticles have also been used to investigate the penetration of the blood-brain barrier in mice, with a view to treating Alzheimer's disease and to preventing the formation of brain tumors. ${ }^{7}$ The in vitro antihepatoma activities of curcumin polyvinylpyrrolidone nanoparticles have also been investigated. ${ }^{9}$

A new generation of targeted drug carriers is beginning to exploit nanotechnology to reduce systemic overdosage of drugs,${ }^{11}$ by supplying an effective concentration locally at the site of disease. Maintenance of the proper concentration of bioactive molecules and targeting to disease sites may both be improved using an external means to supply energy (such as a magnetic field, ${ }^{12}$ light, ${ }^{13}$ or sound waves ${ }^{14,15}$ ). The possibility presents itself that locally delivered curcumin might be an effective cancer treatment. Local concentrations could, in principle, be sufficient to kill tumor cells, and the antioxidant effects of curcumin would be beneficial to nearby nontumor cells. We have chosen to study ultrasound as a potential release modality for a lipid-based (here, a lipid emulsion) carrier. Ultrasound has been fairly extensively studied and can provide a "direct" release mechanism or act via local hyperthermia to enhance the delivery of specific formulations, as described previously. Incorporation of poly(ethylene glycol)containing surfactants appears to enhance the sensitivity of lipid-based carriers to sound, ${ }^{16}$ possibly by interfering with the "healing" of membrane defects. Emulsions are drawing increased attention, and so-called phase-shift emulsions (generally containing low boiling point fluorocarbons) can give ultrasound-triggered release when emulsion droplets vaporize in response to insonation. ${ }^{17}$ Ganta and Amiji ${ }^{18}$ have used a combination of paclitaxel and curcumin in nanoemulsion formulations to overcome multidrug resistance in $\mathrm{SKOV} 3_{\mathrm{TR}}$ ovarian adenocarcinoma cells.

This investigation considers the stability and effects of low-frequency ultrasound on a curcumin microemulsion. ${ }^{15}$ A carrier oil was used to solubilize the curcumin. Soybean oil (listed as generally recognized as safe) was used, rather than ethyle oleate, which is not currently approved by the Food and Drug Administration for any injectable use and is regulated as a food additive. The sound intensity required to release curcumin from the curcumin microemulsions to two oral squamous carcinoma cell lines (OSCC-4 and OSCC-25) was also examined. Finally, dosages and the synergy between ultrasound and curcumin microemulsions were studied to determine the efficacy of this method for the localized delivery of curcumin.

\section{Materials and methods Lipids and chemicals}

Soybean lecithin (L- $\alpha$-phosphatidylcholine and inositol phospholipids, purity $>80 \%$ ) (sourced from natural plant soybean oil) and soybean oil were obtained from Taiwan Sugar Corporation (Tainan, Taiwan) and Uni-President Corporation (Tainan), respectively. Both are food-grade products. Tween 80 and curcumin powder of $70 \%$ purity were purchased from Sigma-Aldrich Chemical Co (St Louis, MO) and Fluka (Seelze, Germany). OSCC-4 and OSCC25 cell lines (\#60142 and \#60516) were purchased from Bioresource Collection and Research Center (Hsinchu, Taiwan). The culture medium for OSCC cell lines contains $44 \%$ of both Dulbecco's modified Eagle's medium and Ham's F12 medium, 2.5 mM L-glutamine, 15 mM HEPES (powder from Gibco), $1.2 \mathrm{~g} / \mathrm{L}$ sodium bicarbonate, 10\% fetal bovine serum, 1\% nonessential amino acid (Invitrogen, Carlsbad, CA), and 1\% penicillin/streptomycin. The last three chemicals are also from Sigma-Aldrich Chemical Co. Dimethyl sulfoxide (DMSO, product \#161954) was purchased from Panreac (Barcelona, Spain).

\section{Preparation of curcumin microemulsions}

Deionized water, soybean oil, soybean lecithin, and Tween 80 as surfactants, and curcumin, in amounts indicated in Figure 1 (vide infra), were placed in a test tube $(10 \mathrm{~mm} \times 120 \mathrm{~mm})$ and well mixed at $50^{\circ} \mathrm{C}$ using a vortex mixer at $100 \mathrm{rpm}$ for 5-20 minutes to form curcumin microemulsions. The curcumin microemulsion had a transparent appearance with a yellow tint.

\section{Stability of curcumin microemulsions measured by size distribution and zeta potential}

The size distribution and zeta potential of curcumin microemulsions were studied with a particle sizer and a zeta potential analyzer (90Plus and ZetaPlus, Brookhaven Instruments Co, New York, NY), equipped with a $532 \mathrm{~nm}$ laser light source. The scattering laser power of this instrument is the standard $35 \mathrm{~mW}$ laser but adjusted to $25 \mathrm{~mW}$. The 90Plus particle sizer uses dynamic light scattering, with collection times for the autocorrelation function of 1-3 minutes at the 


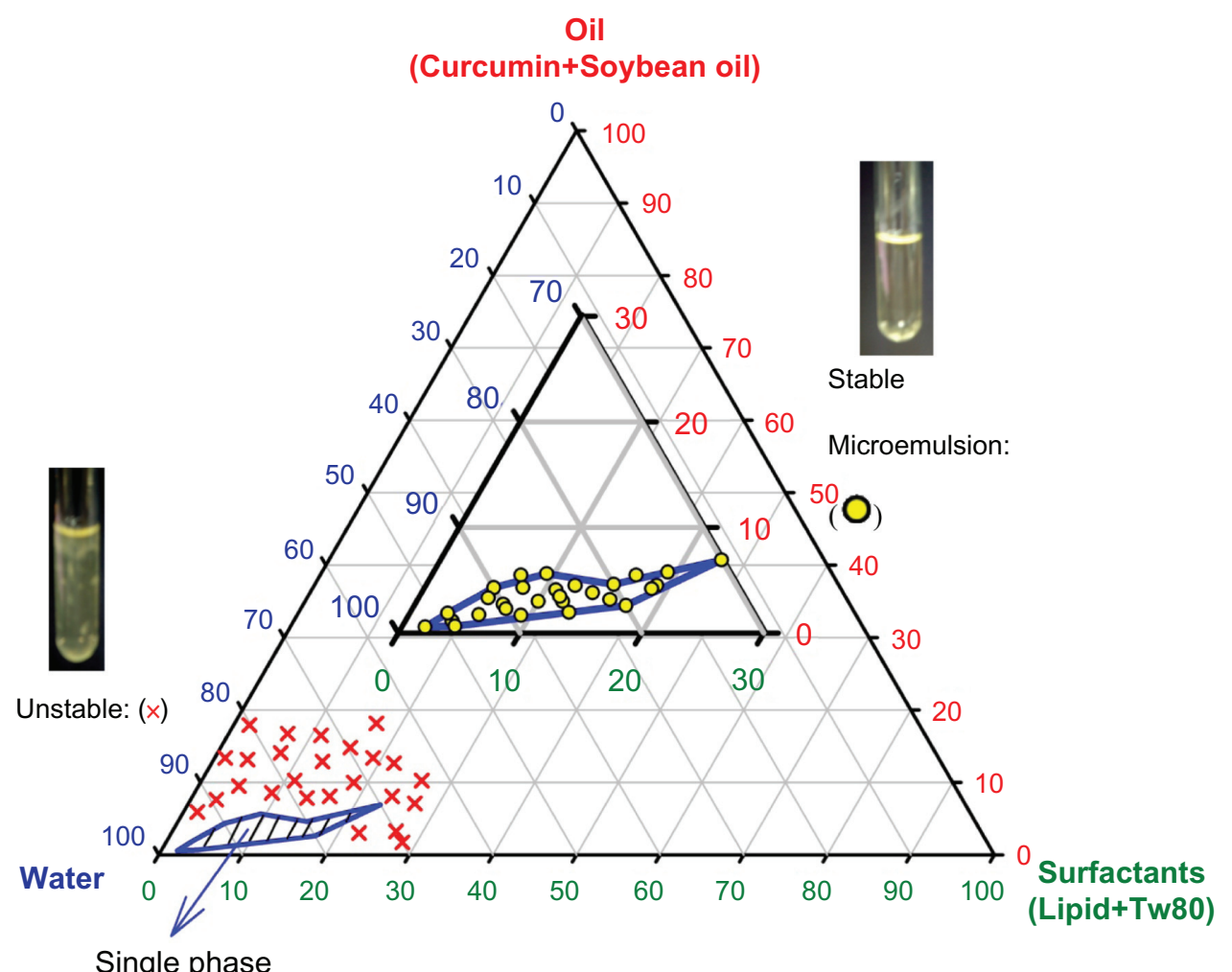

Figure I Stability of emulsions made from oil (soybean oil plus curcumin)/water/surfactants (lecithin plus Tween 80 ), stored at $25^{\circ} \mathrm{C}$. Microemulsions shown as open circles were found to be stable; $(\times)$ : microemulsions were unstable.

Note: Tween 80 :lecithin ratios were varied from I:I to $24: 1$, with no significant change in microemulsion stability with the same total surfactant.

$90^{\circ}$ scattering angle. The average count rate of the background was $3 \mathrm{kcps}$, and that of each measurement was between 20 $\mathrm{kcps}$ and $500 \mathrm{kcps}$. The correlator covers the equivalent of $10^{7}$ linearly spaced channels. Real-time operation over the entire delay-time range corresponding to particle sizes between $1 \mathrm{~nm}$ and $6000 \mathrm{~nm}$ was chosen.

It is also important to assess whether microemulsions are sufficiently stable in the presence of serum proteins. For this purpose, a solution of (bovine serum) albumin was prepared at $5 \mathrm{mg} / \mathrm{mL}$ in phosphate buffered saline (PBS) solution at $\mathrm{pH}$ 7.4. Curcumin microemulsion in amounts of $0.1 \mathrm{~mL}, 0.2 \mathrm{~mL}, 1 \mathrm{~mL}$, and $2 \mathrm{~mL}$ was added into $5 \mathrm{~mL}$ albumin solution, and emulsion sizes were measured 0-7 days after preparation.

\section{Curcumin release from microemulsions under insonation}

The $40 \mathrm{kHz}$ ultrasonic processor (Model VC134, Sonics and Materials Inc, Newtown, CT) with a "standard" probe (Ti-6 Al-4V) of $3 \mathrm{~mm}$ diameter was immersed into a $1 \mathrm{~cm}$ polystyrene cuvette. The probe was immersed approximately $1 \mathrm{~cm}$ into a $1.5 \mathrm{~mL}$ sample, initially containing only PBS $\left(65 \mathrm{mM} \mathrm{NaCl}\right.$ and $50 \mathrm{mM} \mathrm{KH}_{2} \mathrm{PO}_{4}$ at $\left.\mathrm{pH} 7.4\right)$.
After adding $300 \mu \mathrm{L}$ of microemulsion stock solution (to a dilution of $6 \times)$, ultrasound was then applied at either $20 \%\left(\sim 1.9 \mathrm{~W} / \mathrm{cm}^{2}\right)$ of full power for 5 seconds, 10 seconds, 15 seconds, and 20 seconds. Released curcumin forms insoluble aggregates, which float to the surface of the sample. The resultant solution was passed through a $0.45 \mu \mathrm{m}$ filter and then subjected to high-pressure liquid chromatography $^{19}$ (Hitachi L-2130 pump, L-2420 UV/VIS detector, and LiChrospher 100-5 R C-18 column). The separation was performed on a Cosmosil 5C18 MS column (5 $\mu \mathrm{m}$, $25 \mathrm{~cm} \times 4.6 \mathrm{~mm}$ ID, Nacalai Tesque, Kyoto, Japan). The sample $(20 \mu \mathrm{L})$ was eluted with a mobile phase composed of $0.1 \% \mathrm{H}_{3} \mathrm{PO}_{4}(40 \%)$ and acetonitrile $(60 \%)$. The flow rate and detection wavelength were set to be $1.0 \mathrm{~mL} /$ minute and $420 \mathrm{~nm}$, respectively. ${ }^{20}$ The standard curves of curcumin in DMSO ranging from $0.01 \mathrm{mg} / \mathrm{mL}$ to $1.0 \mathrm{mg} / \mathrm{mL}$ were used for calibration. The retention time for curcumin is 12.3 minutes.

The droplet morphologies of the curcumin microemulsions were determined using transmission electron microscopy (TEM). A total of $5 \mu \mathrm{L}$ of curcumin microemulsion was placed on 200 mesh formvar carbon-coated copper grids for 10 minutes, and then negative stained with $5 \mu \mathrm{L}$ of 
2\% uranyl acetate for 10 minutes at room temperature. The excess liquid on the samples was wiped off with a filter paper, and then samples were air-dryed for 30 minutes. The grid containing the microemulsion droplets was observed with a field emission scanning electron microscope (FE-SEM) S-4800 (Hitachi, Japan) and TEM H-7500 (Hitachi).

\section{MTT (cytotoxicity) test of OSCC with curcumin microemulsions after insonation}

The MTT test $(97.50 \%$ purity from Sigma-Aldrich Chemical $\mathrm{Co}$ ) is used as a rapid and sensitive method for screening curcumin microemulsions and ultrasound effects on OSCC-4 and OSCC- 25 cells. About $2 \times 10^{4}$ OSCC cells were added to the 96-well culture plate (Nalge Nunc International, Rochester, NY) and incubated $\left(37^{\circ} \mathrm{C}\right.$ and $\left.5 \% \mathrm{CO}_{2}\right)$ for 24 hours. A total volume of $30 \mu \mathrm{L}$, consisting of differing amounts of curcumin microemulsion and PBS, was added. Samples were insonated and then incubated for another 24 hours. MTT solution $(50 \mu \mathrm{L})$ was added to each well and incubated with cells for 3 hours. Medium was removed and $100 \mu \mathrm{L}$ DMSO was added. Absorption at signal and reference wavelengths (570 $\mathrm{nm}$ and $620 \mathrm{~nm}$, respectively) was measured with an ELISA reader (Power Wave HT340, BioTek, Winooski, VT). Effective absorption is obtained by subtracting the reference absorption from the signal. The cellular viability (\%) was then calculated from the ratio of effective absorption of experimental cells to controls. The temperature was measured after insonation using the dual input digital thermometer DTM 315 (Tecpel Co, Taiwan).

All data were analyzed by Student's $t$-test using SPSS statistics software (SPSS, Inc, Chicago, IL).

\section{Results and discussion}

Microemulsions are good candidate drug carriers because of their nanometer size, which enhances the kinetics of drug absorption/desorption and may also increase the loading capacity for surface active drugs. ${ }^{21}$ In addition, small size allows passage through organ filtering systems, and extravasation through tumor vasculature, both of which are highly desirable characteristics. Most anticancer drugs are hydrophobic or amphiphilic, and micelle carriers may encapsulate much higher concentrations of a drug than other carriers. In this paper we have focused on emulsions of soybean oil in water as carriers for a potentially useful anticancer agent, curcumin.

Figure 1 shows the compositions for which we obtained stable oil-in-water microemulsions. Unstable formulations rapidly separate into water and oil phases that can be visually observed. The stable microemulsions contain oil and surfactant concentrations of less than $\sim 8 \mathrm{wt} \%$ and $30 \mathrm{wt} \%$, respectively. To carry more drugs in the microemulsions, the oil content must be as high as possible, but increasing the concentration of oil may cause instability and require that more surfactants be used, increasing total cost. Microemulsions that contained $2.5 \mathrm{wt} \%$ oil and $15 \mathrm{wt} \%$ surfactants were chosen to be used in an in vitro test with the OSCC cell lines, with curcumin dissolved in the oil phase to $0.27 \mathrm{mg} / \mathrm{mL}$, the highest concentration that is fully soluble. As the oil-water partition coefficient of curcumin is $\sim 2000$, almost all of the curcumin should remain in the microemulsion droplets. The total concentration of emulsified curcumin was $15 \mu \mathrm{M}$.

Figure 2A displays the stability in the size and zeta potential of these microemulsions. Light scattering measurements of the mean size of the curcumin microemulsions gave $41 \pm 3 \mathrm{~nm}$ to $51 \pm 2 \mathrm{~nm}$, measured at various times during a 968 -day storage at $5^{\circ} \mathrm{C}$. The zeta potential exhibits good to moderate stability after 968 days of storage, though there is a small but statistically significant decrease in zeta potential over 40 days, from $-42.12 \pm 1.26 \mathrm{mV}$ to $-32.58 \pm 3.89 \mathrm{mV}$. This negative zeta potential arises from the incorporation of lecithin in the microemulsion, as lecithin micelles/suspensions were also found to have zeta potential, from $-36.2 \pm 2.7 \mathrm{mV}$ to $-59.9 \pm 3.8 \mathrm{mV}$. Although there is some change in the size and zeta potential over long periods, these changes are small and do not necessarily indicate that these emulsions are "unstable." In practice, emulsions are considered "moderately stable" if the magnitude of the zeta potential exceeds $30 \mathrm{mV}$ (American Society for Testing and Materials standard), ${ }^{19-21}$ as zeta potentials this large strongly inhibit coalescence.

For potential applications of microemulsions in drug delivery, the stability of the microemulsion in the presence of serum proteins is critical. We measured the stabilities of these curcumin-encapsulated microemulsions after dilution into a $5 \mathrm{mg} / \mathrm{mL}$ albumin solution by measuring droplet size, after storage in the dark for 0-7 days, as shown in Figure 2B. Although there was a slight decrease in the measured droplet size, there was no evidence of droplet coalescence, ripening, or gross instability.

Figure 3 shows the effects of ultrasound on newly prepared curcumin microemulsions. The mean particle size decreased dramatically when ultrasound was applied even for only a few seconds, from $44 \pm 3 \mathrm{~nm}$ to $26 \pm 2 \mathrm{~nm}$ in 20 seconds when insonated at $20 \%$ of full power at $40 \mathrm{kHz}$ (Figure 3). The light scattering polydispersity index (an estimate of the width of the distribution) of the curcumin microemulsion 

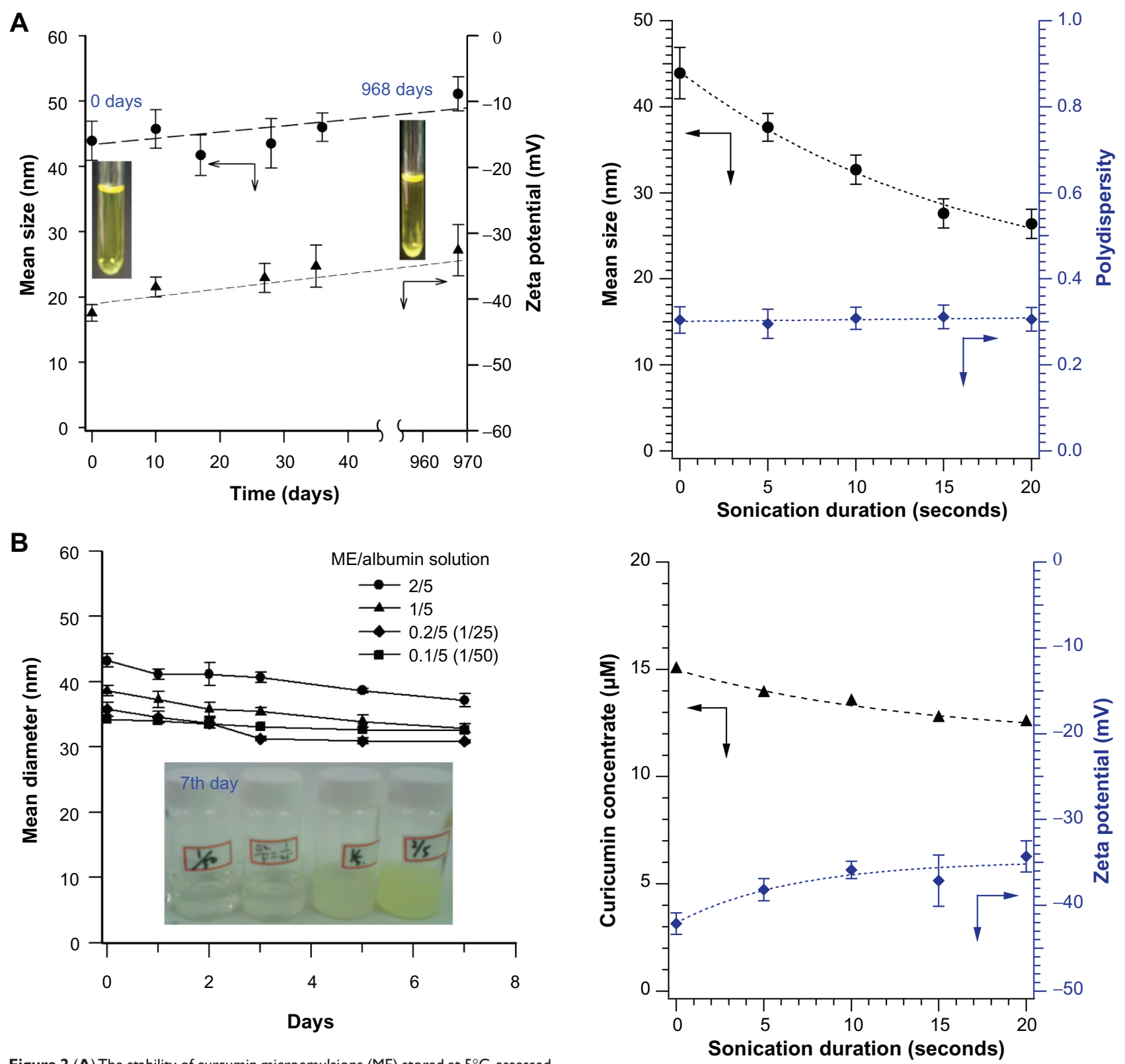

Figure 2 (A) The stability of curcumin microemulsions (ME) stored at $5^{\circ} \mathrm{C}$, assessed by measurements of mean particle size (top curve, left axis) and zeta potential (lower curve, right axis.) The size is very stable. The zeta potential shows only a slight decrease in magnitude over 968 days. (B) The stability of ME when stored in albumin solutions, as assayed by droplet size.

was $0.327-0.331$, regardless of the application of ultrasound, which is considered a moderate polydispersity. Sixty-six percent of the microemulsion particles are within $\pm 9-14 \mathrm{~nm}$ of the light scattering peak size. Figure 3B shows that the magnitude of the zeta potential decreased slightly, from $-42.12 \pm 1.26 \mathrm{mV}$ to $-34.29 \pm 1.82 \mathrm{mV}$, on insonation. Absorption measurements showed that the micellized curcumin concentration decreased from $15.0 \mu \mathrm{M}$ to $12.5 \mu \mathrm{M}$ (released curcumin is insoluble and forms a floating aggregate out of the ultraviolet-visible probe beam). The decrease in particle size may be related to the well-known breakup of

Figure 3 (A) Mean sizes (black circles) and polydispersity (green squares); (B) curcumin concentrations (black triangles) and zeta potentials (blue diamonds) of curcumin microemulsions after brief insonation.

bubbles in ultrasound, which can occur through the parametric amplification of surface modes. ${ }^{22,23}$ It is less clear why droplet breakup leads to release and aggregation of curcumin, but it is certainly plausible that the increased surface exposure (caused by dilution of surfactants on the increased surface area of smaller droplets) causes curcumin aggregation, or that curcumin exposure to the aqueous phase is transiently elevated at droplet fission necks or other transient structures.

Figure 4 demonstrates that simply immersing the ultrasonic probe into the cell well has no effect on cell viability, as expected. In the absence of microemulsions, ultrasound 

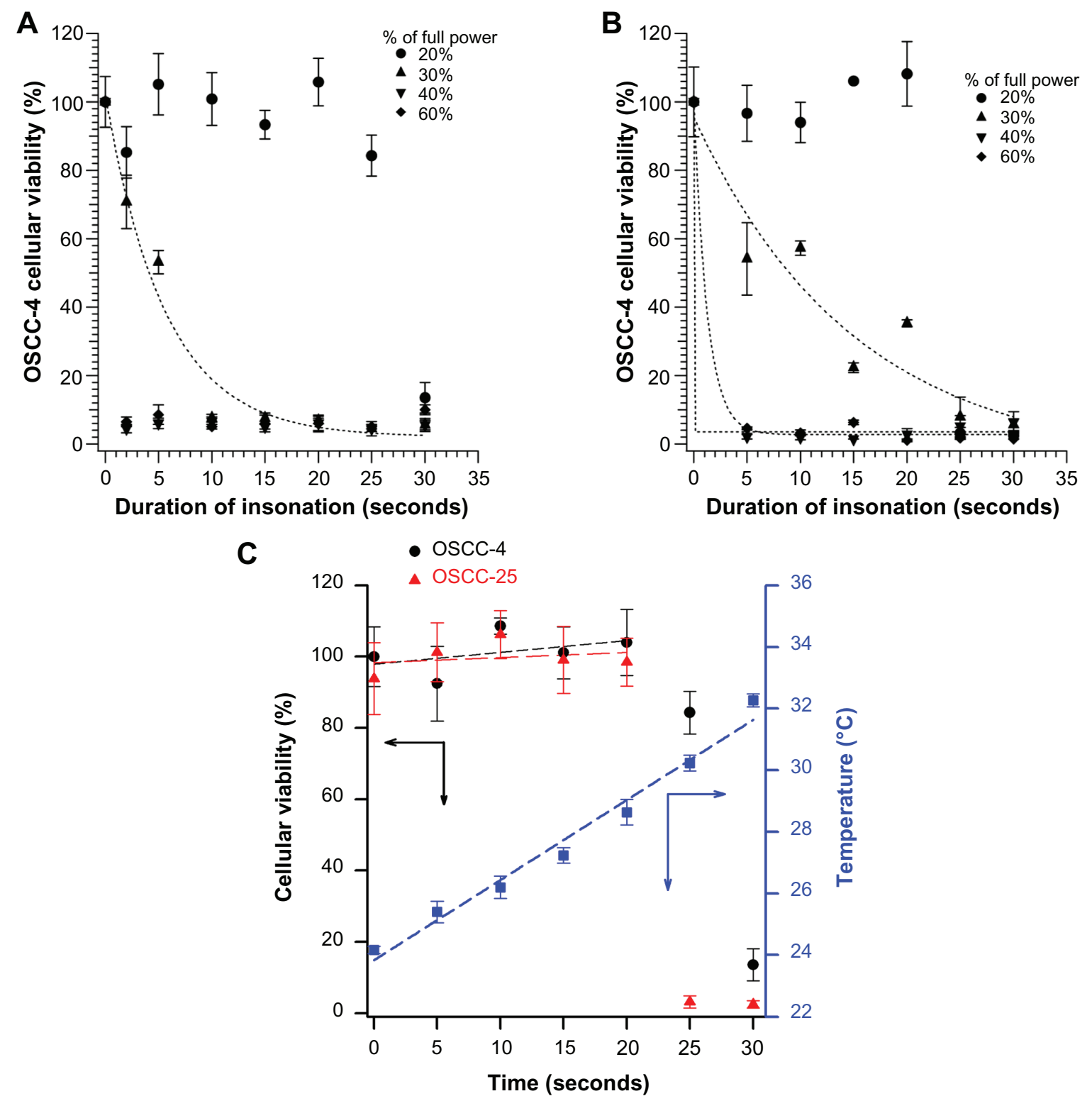

Figure 4 The MTT viability test results on (A) oral squamous cell carcinoma-4 and (B) oral squamous cell carcinoma- 25 cells after different insonation duration, in buffer alone (without addition of curcumin microemulsion), $20 \%$ (circle), $30 \%$ (upper triangle), $40 \%$ (lower triangle), and $60 \%$ (diamond) of full sound power. (C) The sudden decrease in viability after 20 seconds of insonation at $20 \%$ power may be caused by a temperature increase; the temperature increases nearly $6^{\circ} \mathrm{C}$ in this time.

applied at the $20 \%$ power setting gave good cell viability until 20 seconds of insonation, for both cell lines (Figure 4A and B, circles). (Because of the rather long wavelength of this lowfrequency $40 \mathrm{kHz}$ ultrasound, all cells in a well [in the 96-well plate] should experience approximately the same sound field.) The rather unusual dose response, with essentially no effects after $<20$ seconds of exposure, suggests that an indirect ultrasound effect, such as a temperature rise greater than $4.2^{\circ}$ (in Figure 4C), may actually be the cause of the loss of viability after 20 seconds of exposure. Higher intensities of ultrasound caused cell viability to drop after shorter exposures. For $\geq 40 \%$ of full power, only 2 seconds of exposure was sufficient to kill essentially all the cells. At $30 \%$ of full power, cell viability decayed more gradually with increasing exposure.

Figure $5 \mathrm{~A}$ shows that the size distribution of microemulsion droplets shifts to smaller sizes on applying ultrasound from 0 seconds to 20 seconds. The uranyl acetate negative stain enhances contrast. The FE-SEM (insert) and TEM show the spherical morphology of the microemulsion droplets without ultrasound (Figure 5B). After 10 seconds of ultrasound, the sample floating to the surface was picked up on an electron microscope grid and imaged. The FE-SEM image (Figure 5C) shows that the released curcumin in soybean oil is aggregated, with a droplet size larger than that of microemulsion droplets. 


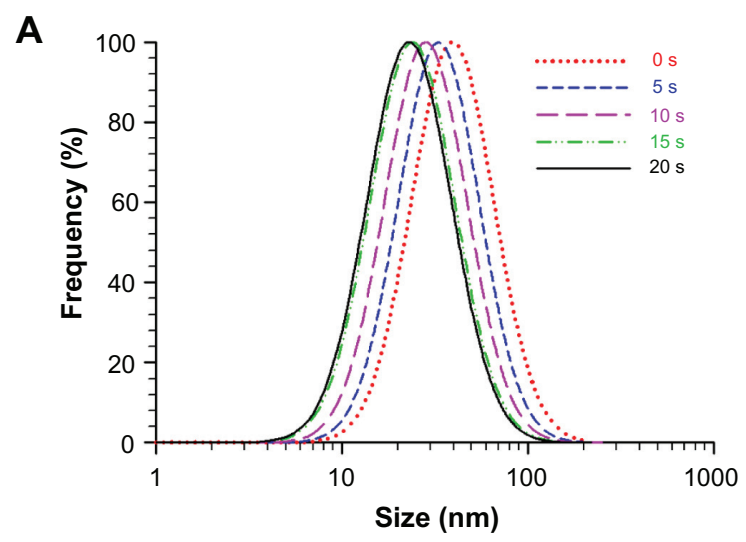

B

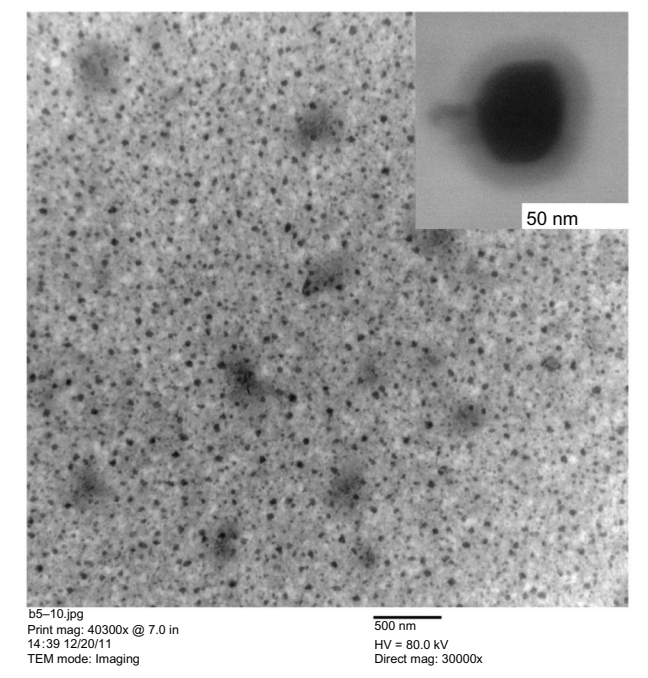

C

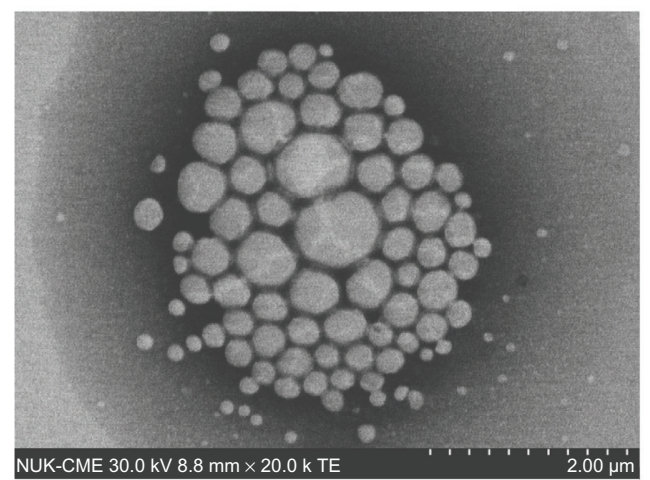

Figure 5 (A) Size distributions (from cumulant analysis of light scattering data) of microemulsion droplets, applying ultrasound from 0 seconds to 20 seconds, (B) the field emission scanning electron microscopy (insert) and transmission electron microscopy of curcumin micoremulsion without ultrasound, $(\mathbf{C})$ after 10 seconds of ultrasound, the released material (essentially soybean oil) floats to the surface and is picked up on a grid and imaged by field emission scanning electron microscopy.

Likely owing to its near complete insolubility in water, curcumin alone has no statistically significant effect on cell survival or growth, in either the presence or absence of ultrasound for 20 seconds at $20 \%$ full power (data not shown). When curcumin was first dissolved in DMSO and then dispersed into cell cultures, a small reduction in cell growth $(25 \%)$ was seen, but only at the highest curcumin concentration studies $(15 \mu \mathrm{M})$, only in the presence of ultrasound, and only on the OSCC-25 cell line. Unlike free curcumin or curcumin in DMSO, curcumin microemulsions are toxic to cells (Figure 6, open symbols). This toxicity may be a consequence of the increased delivery of curcumin to the cell, perhaps via fusion of microemulsion droplets with cell membranes. When $40 \mathrm{kHz}$ ultrasound (power level $\left.20 \%, \sim 1.9 \mathrm{~W} / \mathrm{cm}^{2}\right)$ is applied for 20 seconds, the cytotoxic
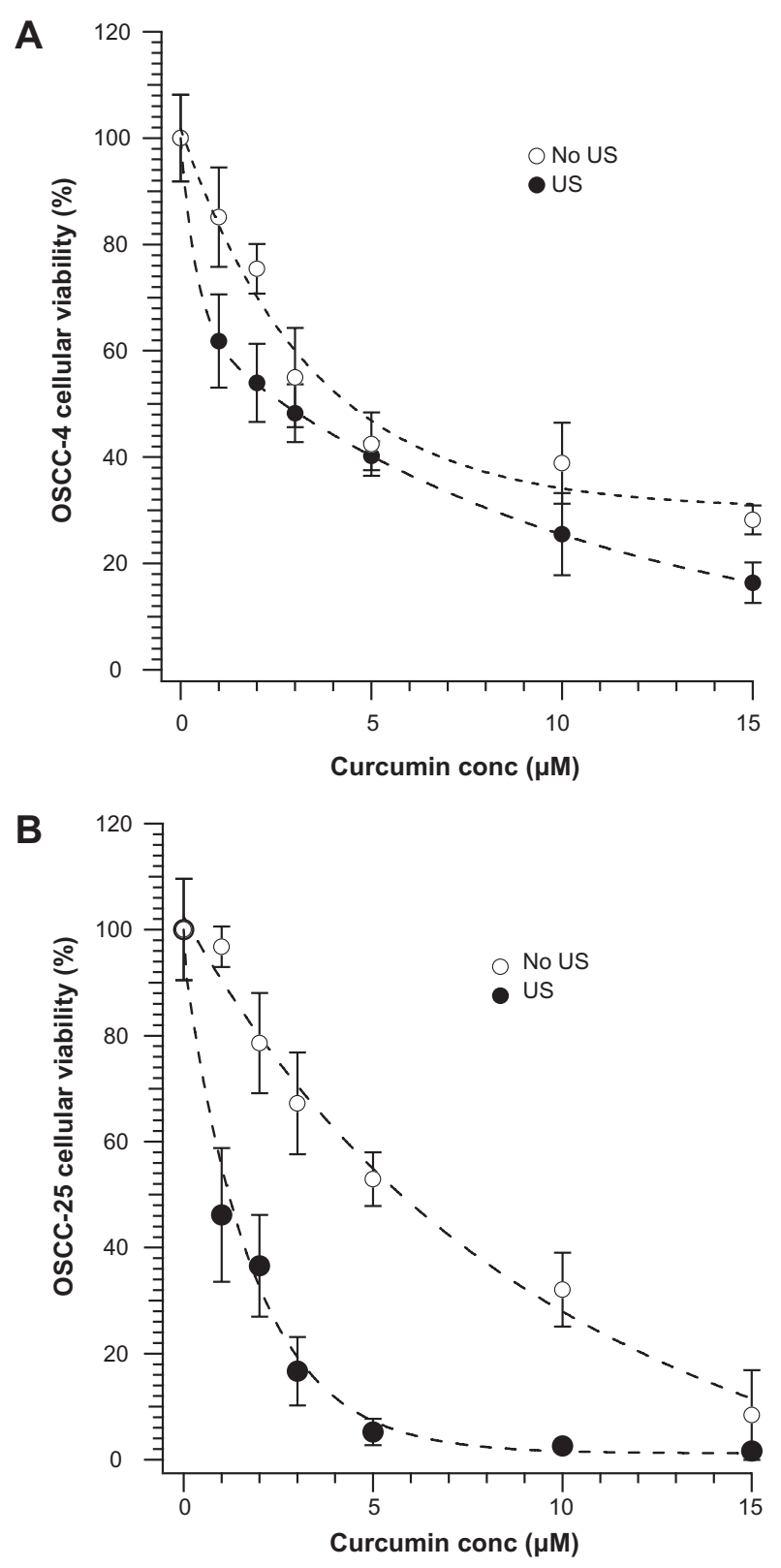

Figure 6 Viability (via MTT test) of cells after treatment with different concentrations of curcumin-containing microemulsions. Cells in 96-well plates were treated with different dilutions (in phosphate buffered saline) of a $15 \mu \mathrm{M}$ curcumin microemulsion, then exposed or not to ultrasound (US) at $20 \%$ power level for 20 seconds: (A) oral squamous cell carcinoma (OSCC)-4 and (B) OSCC- 25 cell lines.

Note: The OSCC-25 cell line had a decrease of about a factor of six in the LD50 for the microemulsion. 
effects of the curcumin microemulsions are enhanced (solid symbols). The enhancement is particularly dramatic for the OSCC-25 cells, for which the LD50 dropped from about $6 \mu \mathrm{M}$ to $1 \mu \mathrm{M}$. To evaluate the statistical significance of the viability change in each cell line, the data at each curcumin concentration were compared using Student's $t$-test. On OSCC-4 cells, the effect at each concentration has rather weak statistical significance (especially when error bars overlap, eg, at $3 \mu \mathrm{M}, 5 \mu \mathrm{M}$, and $10 \mu \mathrm{M}$ curcumin). However, the probability of the null hypothesis (ie, that ultrasound has no effect on viability) is obtained as the product of the individual $P$-values for the points and is $<0.008$. Thus, there is a small but statistically significant effect of ultrasound on enhancing the cytotoxicity of curcumin microemulsion. At most curcumin concentrations, the cytotoxicity increased by $>25 \%$ for the OSCC- 4 cells.

The effect of ultrasound on the OSCC-25 cell line had even greater statistical significance $(P<0.002)$ when analyzed by Student's $t$-test (Figure 6B). Note that exposure of cells to microemulsions without curcumin, for this length of time, is not toxic.

In liposomally based ultrasound delivery, a threshold in sound intensity for efficacy has been reported, ${ }^{15,24}$ which likely indicates that ultrasound-induced cavitation is required. Interestingly, the intensities that are effective with curcumin microemulsions range from below cavitational to well above it. The higher intensities (such as are shown in Figure 4B and $4 \mathrm{~B}, \geq 30 \%$ maximum power) are lethal to cells even at the briefest exposures studied and likely cause cavitation, whereas the $20 \%$ power setting gave no measurable cell death for short exposures. (The $20 \%$ power setting on this sonicator probe provides $1.9 \mathrm{~W} / \mathrm{cm}^{2}$, which is below the typical cavitation threshold; moreover, the identical sonicator had no effects on liposomes at this power level, implying a lack of cavitation.)

Our results imply that ultrasound is enhancing the delivery of cytotoxic concentrations of curcumin to cells. Ultrasound-enhanced delivery at subcavitating intensities is not unprecedented; effects on drug release from micelles has been reported, for example. ${ }^{25}$ It is interesting and noteworthy that ultrasound caused directly measurable changes in emulsion droplet size and loss of dissolved curcumin, as we show in Figure 3B, though of course we cannot be certain that such release of curcumin is in fact a prerequisite to the ultrasoundmediated delivery to the cells. It is always possible that direct contact between cells and microemulsion droplets, followed by insonation, leads to the fusion of a droplet with the cell and delivery of the curcumin cargo.
Figure 7 displays optical microscopy images of OSCC-25 cells with curcumin concentrations (from top to bottom: $0 \mu \mathrm{M}, 5 \mu \mathrm{M}, 10 \mu \mathrm{M}$, and $15 \mu \mathrm{M})$ without (left column) and with sonication (right column). As can be seen from the microscope images, higher curcumin concentrations induce greater cellular lysis. For a particular applied curcumin concentration, ultrasound enhanced the toxicity effect and fewer cells are observed, as in Figure 7D and $\mathrm{H}$.

Figure 8 highlights the synergistic effects of curcumincontaining microemulsions and ultrasound. Shown are cell viabilities for cells treated with curcumin-free microemulsions without ultrasound, curcumin-free microemulsions and ultrasound ( 20 seconds at $20 \%$ power, $\sim 1.9 \mathrm{~W} / \mathrm{cm}^{2}$ ), curcumincontaining microemulsions without ultrasound, and curcumincontaining microemulsions with the low-intensity ultrasound treatment. Adding the curcumin-free microemulsion into OSCC cell lines, the "viabilities" of OSCC-4 and OSCC-25 cell lines were actually increased to $>100 \%$ by sonication. (Viabilities $>100 \%$ simply reflect that more live, healthy cells were counted after treatment than before.) This clearly shows that microemulsions alone are not harmful to the cells. The increased cell growth is consistent with previous reports that low-intensity ultrasound can sometimes enhance cell metabolism and proliferation. ${ }^{26,27}$ Brief exposure to the curcumin-containing microemulsions did have cytotoxic effects, but the addition of ultrasound strongly enhanced those effects, as shown in Figure 8. Continuous low-frequency sound waves effectively induced the release of curcumin from microemulsions. A lower-intensity (about $20 \%$ of full power) and shorter sonication duration ( 20 seconds) does not damage OSCC-4 and OSCC- 25 cells, as determined by monitoring 24 hours after application of the sound, but did enhance the toxicity of the curcumin-containing microemulsions. With the OSCC-25 cell line, the LD50 was reduced by about a factor of six. Comparison of the expression of fatty acid synthase ${ }^{28}$ and activated transforming growth factor- $\beta 1$ signaling ${ }^{29}$ has shown that OSCC-25 is a more aggressive tumor cell line than OSCC-4. These differences may be related to the differential efficacy of ultrasound on the two lines.

The increased cytotoxicity of curcumin microemulsions in the presence of ultrasound could arise from an enhanced fusion of microemulsion droplets to cell membranes, or simply from amelioration of transport limitations by ultrasound-induced mixing and/or heating. It is noteworthy that enhancements were seen even for 5 seconds of ultrasound exposure, which argues against a simple heating mechanism (as temperature increases with duration of exposure). 


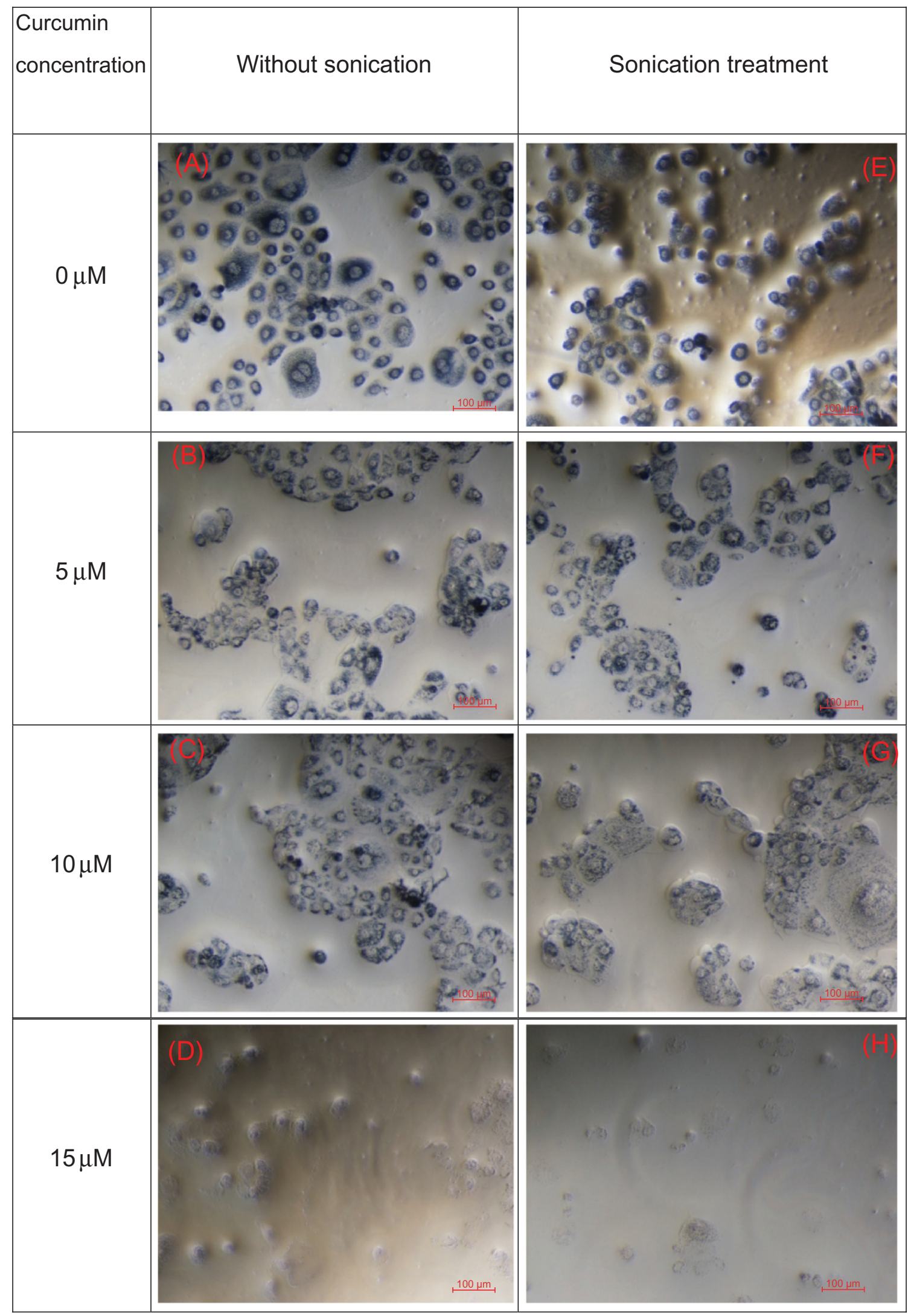

Figure 7 Optical microscope images of oral squamous cell carcinoma- 25 cell lines stained by trypan blue; (A-D) show the microscopic images of cells with curcumin concentrations at $0 \mu \mathrm{M}, 5 \mu \mathrm{M}, 10 \mu \mathrm{M}$, and $150 \mu \mathrm{M}$ without sonication, and $(\mathbf{E}$ and $\mathbf{H})$ show the microscopic images of cells with curcumin concentrations at $0 \mu \mathrm{M}, 5 \mu \mathrm{M}$, $10 \mu \mathrm{M}$, and $15 \mu \mathrm{M}$ after sonication treatment.

Note: Those images show the synergy of microemulsion treatment with ultrasound in producing cytotoxicity. 
A

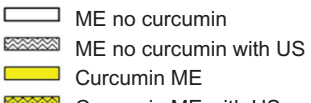

Curcumin ME

Curcumin ME with US

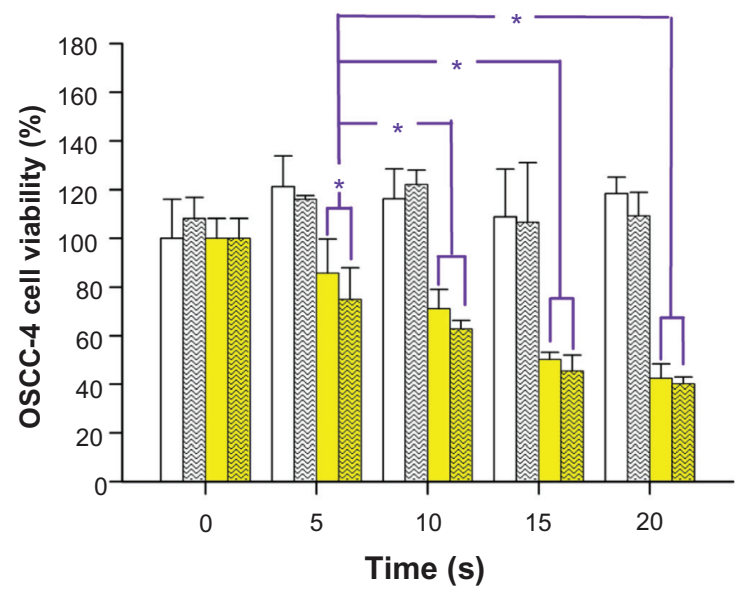

B

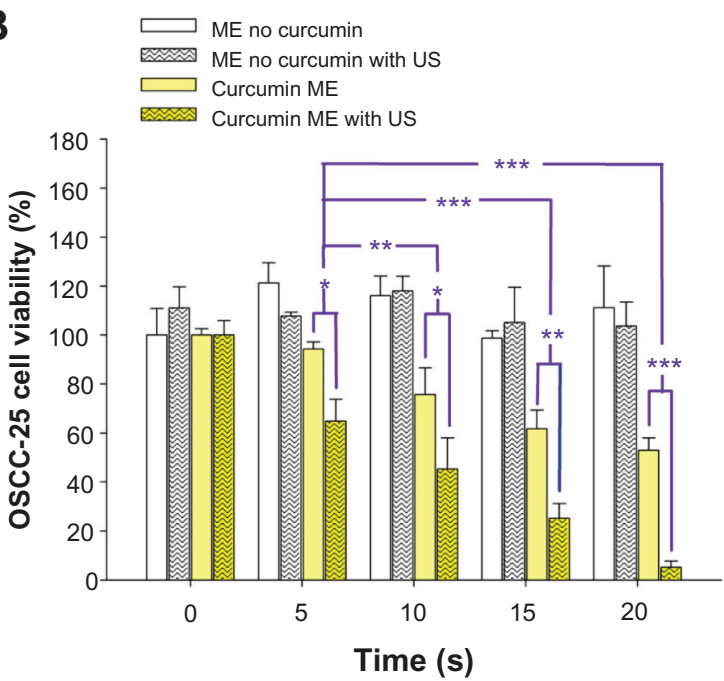

Figure 8 The cellular viability (via MTT test) when (A) oral squamous cell carcinoma (OSCC)-4 and (B) OSCC-25 cell lines were treated with curcumin-free microemulsions (ME) without ultrasound (US) (control), curcumin-free ME and US, curcumin-containing ME (5 $\mu$ M curcumin) without US, and curcumin-containing ME with insonation.

Notes: Comparing curcumin-free and curcumin-containing groups at the same US condition, the curcumin-containing ME at OSCC- 4 and OSCC- 25 cell lines were significantly different $(* P<0.05$, $* * P<0.006$, *** $P<0.002)$ when analyzed by Student's t-test.

\section{Conclusion}

The application of ultrasound to enhance drug delivery is attractive, as intensities and durations of exposure can often be chosen so as to minimize damage to healthy tissues. For oral cancer, the ultrasound-enhanced delivery of curcumin as a cytotoxic agent is appealing, as the microemulsion could be ingested orally and the concentration adjusted so as to have little effect on healthy tissues in the absence of the ultrasound release trigger. In this study we determined what compositions of curcumin-containing microemulsions are stable and thus usable in this kind of application. Moreover, the ingredients are all biocompatible, to reduce the side effects. The stable microemulsions were characterized by their mean droplet size and zeta potential, and these were found to be fairly stable after 968 days in a freezer. The effect of sound on the release of curcumin may help to maintain the effective concentration for the chemotherapy, especially for the more aggressive cell lines (eg, OSCC-25). Additionally, the in vitro controlled release of drugs (thought of as simply bioactive molecules) may be useful in cellular molecular therapy in tissue engineering.

\section{Acknowledgments}

The authors would like to acknowledge the National Science Council of the Republic of China, Taiwan, for financially supporting this research under Contract Nos. NSC 97-2320-B-390-001-MY3, and NSC 100-2221-E-214-032-.

\section{Disclosure}

The authors report no conflicts of interest in this work.

\section{References}

1. Aggarwal BB, Shishodia S. Molecular targets of dietary agents for prevention and therapy of cancer. Biochem Pharmacol. 2006;71(10):1397-1421.

2. Huang MT, Lou YR, Ma W, Newmark HL, Reuhl KR, Conney AH. Inhibitory effects of dietary curcumin on forestomach, duodenal, and colon carcinogenesis in mice. Cancer Res. 1994;54(22):5841-5847.

3. Ganta S, Devalapally H, Amiji M. Curcumin enhances oral bioavailability and anti-tumor therapeutic efficacy of paclitaxel upon administration in nanoemulsion formulation. J Pharm Sci. 2010;99(11):4630-4641.

4. Gota VS, Maru GB, Soni TG, Gandhi TR, Kochar N, Agarwal MG. Safety and pharmacokinetics of a solid lipid curcumin particle formulation in osteosarcoma patients and healthy volunteers. J Agric Food Chem. 2010;58(4):2095-2099.

5. Donsì F, Wang Y, Li J, Huang Q. Preparation of curcumin sub-micrometer dispersions by high-pressure homogenization. J Agric Food Chem. 2010;58(5):2848-2853.

6. Konwarh R, Saikia JP, Karak N, Konwar BK. Poly(ethylene glycol)magnetic nanoparticles-curcumin trio: Directed morphogenesis and synergistic free-radical scavenging. Colloids Surf B Biointerfaces. 2010;81(2):578-586.

7. Sun M, Gao Y, Guo C, et al. Enhancement of transport of curcumin to brain in mice by poly(n-butylcyanoacrylate) nanoparticle. J Nanopart Res. 2010;12(8):3111-3122.

8. Setthacheewakul S, Mahattanadul S, Phadoongsombut N, Pichayakorn W, Wiwattanapatapee R. Development and evaluation of self-microemulsifying liquid and pellet formulations of curcumin, and absorption studies in rats. Eur J Pharm Biopharm. 2010;76(3):475-485.

9. Yen F-L, Wu T-H, Tzeng C-W, Lin L-T, Lin C-C. Curcumin nanoparticles improve the physicochemical properties of curcumin and effectively enhance its antioxidant and antihepatoma activities. J Agric Food Chem. 2010;58(12):7376-7382.

10. Takahashi M, Uechi S, Takara K, Asikin Y, Wada K. Evaluation of an oral carrier system in rats: bioavailability and antioxidant properties of liposome-encapsulated curcumin. J Agric Food Chem. 2009;57(19):9141-9146.

11. Shi J, Votruba AR, Farokhzad OC, Langer R. Nanotechnology in drug delivery and tissue engineering: from discovery to applications. Nano Letters. 2010;10(9):3223-3230. 
12. Neuberger T, Schöpf B, Hofmann H, Hofmann M, von Rechenberg B. Superparamagnetic nanoparticles for biomedical applications: Possibilities and limitations of a new drug delivery system. J Magn Magn Mater. 2005;293(1):483-496.

13. Kim S, Ohulchanskyy TY, Pudavar HE, Pandey RK, Prasad PN. Organically modified silica nanoparticles co-encapsulating photosensitizing drug and aggregation-enhanced two-photon absorbing fluorescent dye aggregates for two-photon photodynamic therapy. J Am Chem Soc. 2007;129(9):2669-2675.

14. Pitt WG, Husseini GA, Staples BJ. Ultrasonic drug delivery - a general review. Expert Opin Drug Deliv. 2004;1(1):37-56.

15. Lee MH, Lin HY, Chen HC, Thomas JL. Ultrasound mediates the release of curcumin from microemulsions. Langmuir. 2008;24(5):1707-1713.

16. Lin H-Y, Thomas JL. PEG-lipids and oligo(ethylene glycol) surfactants enhance the ultrasonic permeabilizability of liposomes. Langmuir. 2003;19(4):1098-1105.

17. Fabiilli ML, Sebastian IE, Haworth KJ, Kripfgans OD, Carson PL, Brian Fowlkes J. Ultrasonic delivery of a chemotherapeutic agent using acoustic droplet vaporization (ADV). Ultrasonics Symposium (IUS), IEEE International: 2009:101-103.

18. Ganta S, Amiji M. Coadministration of paclitaxel and curcumin in nanoemulsion formulations to overcome multidrug resistance in tumor cells. Mol Pharm. 2009;6(3):928-939.

19. Jayaprakasha GK, Jagan Mohan Rao L, Sakariah KK. Improved HPLC method for the determination of curcumin, demethoxycurcumin, and bisdemethoxycurcumin. J Agric Food Chem. 2002;50(13): 3668-3672.
20. Lin C-C, Lin H-Y, Chen H-C, Yu M-W, Lee M-H. Stability and characterisation of phospholipid-based curcumin-encapsulated microemulsions. Food Chemistry. 2009;116(4):923-928.

21. Csaba N, Garcia-Fuentes M, Alonso MJ. The performance of nanocarriers for transmucosal drug delivery. Expert Opin Drug Deliv. 2006;3(4):463-478.

22. Chomas JE, Dayton P, May D, Ferrara K. Threshold of fragmentation for ultrasonic contrast agents. J Biomed Opt. 2001;6(2):141-150.

23. Versluis M, Goertz DE, Palanchon P, et al. Microbubble shape oscillations excited through ultrasonic parametric driving. Phys Rev E. 2010;82(2 Pt 2):026321. Epub August 30, 2010.

24. Lin HY, Thomas JL. Factors affecting responsivity of unilamellar liposomes to $20 \mathrm{khz}$ ultrasound. Langmuir. 2004;20(15):6100-6106.

25. Husseini GA, Myrup GD, Pitt WG, Christensen DA, Rapoport NY. Factors affecting acoustically triggered release of drugs from polymeric micelles. J Control Release. 2000;69(1):43-52.

26. Sinisterra JV. Application of ultrasound to biotechnology: an overview. Ultrasonics. 1992;30(3):180-185.

27. Liu Y, Takatsuki H, Yoshikoshi A, Wang B, Sakanishi A. Effects of ultrasound on the growth and vacuolar $\mathrm{H}^{+}$-ATPase activity of aloe arborescens callus cells. Colloids Surf B Biointerfaces. 2003;32(2):105-116.

28. Agostini M, Silva SD, Zecchin KG, et al. Fatty acid synthase is required for the proliferation of human oral squamous carcinoma cells. Oral Oncology. 2004;40(7):728-735.

29. Chen MF, Wang WH, Lin PY, Lee KD, Chen WC. Significance of the TGF-beta1-IL-6 axis in oral cancer. Clinical Science. 2012;122(10): $459-472$.
International Journal of Nanomedicine

\section{Publish your work in this journal}

The International Journal of Nanomedicine is an international, peerreviewed journal focusing on the application of nanotechnology in diagnostics, therapeutics, and drug delivery systems throughout the biomedical field. This journal is indexed on PubMed Central, MedLine, CAS, SciSearch $₫$, Current Contents $₫ /$ Clinical Medicine,

\section{Dovepress}

Journal Citation Reports/Science Edition, EMBase, Scopus and the Elsevier Bibliographic databases. The manuscript management system is completely online and includes a very quick and fair peer-review system, which is all easy to use. Visit http://www.dovepress.com/ testimonials.php to read real quotes from published authors 